\title{
A Reflection on Methodological Approaches in Assessing and Implementing Social Sustainability in Historic Public Spaces
}

Solmaz Yadollahi

DOI: $10.1515 / 9783110415278-014$

Published in book: Perceptions of Sustainability in Heritage Studies, Chapter: Disciplinary and Epistemological Perceptions, Publisher: Walter de Gruyter GmbH \& Co KG, Editors: Marie-Theres Albert, pp.159-172

Please cite as:

Yadollahi, S. (2015). A Reflection on Methodological Approaches to Assessing and Implementing Social Sustainability in Historical Public Spaces. In M.-T. Albert, Perceptions of sustainability in heritage studies (Vol. 4, pp. 159-172). De Gruyter. 


\title{
A Reflection on Methodological Approaches in Assessing and Implementing Social Sustainability in Historic Public Spaces
}

\author{
Solmaz Yadollahi
}

\section{Introduction}

The human self is shaped and developed thanks to social interactions with other persons. Although modern technological developments have caused a growing number of social interactions to take place in the virtual public sphere, the unique value of face-to-face interaction is undeniable: it is in physical public space that the members of a society share the control and use of space. Public space is, and historically, has always been a space for practicing social co-existence and a basis for social sustainability.

Furthermore, having been shared by contemporary and past societies, historical public spaces have the exceptional power of connecting generations to one another, and these public spaces, if protected, can extend connections to future generations. In other words, by telling the story of the construction of societies, historical public spaces can be sources of identity for present and future societies.

In this paper, I will clarify, through a literature review, the meaning of public space and reflect on theoretical approaches to and methods of assessing the ability of urban public spaces to enhance social sustainability. I will explain how the definition of public space and approaches to urban planning share concepts with social sustainability. Finally, reflecting on examples of empirical research that attempt to link physical and social components of public spaces, I will point out the methodological strengths and weaknesses in the field.

Given that approaches to and methods of studying public space in urban planning and urban heritage conservation overlap in many areas, I will not separate the two fields here. However, the empirical works presented are examples of research on historical public spaces. The position of this paper towards historical public spaces, urban heritage, and their relationship with social sustainability is based on a dynamic understanding of heritage.

One of the most recent publications on heritage, Understanding Heritage, edited by Marie-Theres Albert and others, gives a comprehensive perspective on the subject of heritage. Through her paradigmatic reflections on the notion of heritage and heritage studies, Albert (2013), views heritage as a dynamically created phenomenon and a cultural process. She links cultural heritage to the concept of "human develop- 
ment", ${ }^{1}$ arguing that "the protection and use of heritage is conceived of as a potential that shapes identities and builds peace" (Albert, 2013, p. 14). She suggests that the notion of heritage protection should be seen in the framework of sustainable development. The following discussion approaches urban heritage in the framework of that understanding of heritage. In other words, urban heritage encompasses the tangible and intangible components of the dynamic city.

The relation between urban heritage and sustainability is discussed in the UNESCO Recommendation on the Historic Urban Landscape (HUL). The HUL approach calls for the sustainable use of urban spaces by changing the focus from the traditional monumental approach to one that takes into account the social and economic development process. In fact, HUL advocates "a new use and enjoyment of the urban space that defines the city as a living heritage” (Bandarin, 2012, p. 224). HUL is an effort to sustainably protect urban heritage for the coming generations, and to balance the forces of conservation and urban development (Turner, 2013).

As defined by the UNESCO Recommendation on the Historic Urban Landscape, urban heritage can be categorized in three main typologies: first, monumental heritage of exceptional value; second, public, open spaces and streets; and third, urban infrastructures (UNESCO, 2011). Accordingly, in this paper, historical public spaces are considered in the context of the second category of urban heritage in the HUL Recommendation.

Viewing historical public spaces as the most dynamic category of urban heritage, in direct relationship with the members of society, this paper attempts to understand how these spaces contribute to social sustainability and asks how effective the currently used methods are in assessing this contribution.

\section{Social sustainability and its relation to public space at a conceptual level}

\section{Social sustainability}

Initiated with the 1972 Stockholm Conference, the concept of "sustainability" became popular through the Brundtland Report on the 1987 United Nations' World Commission on Environment and Development, then evolved in the course of different international meetings. These debates placed the needs of communities and their limits in an ethical framework (WCED, 1987).

1 In the United Nations Development Programme, "human development" is generally understood to mean enlarging people's choices as regards their standard of living, in areas such as health, education and political freedom (UNDP, 2014). 
The environmental aspect dominated the discourses on sustainability from the late 1980s to the mid-1990s, after which the economic aspect attracted the focus of debates. The feature of social sustainability began to be considered more seriously from the mid-2000s onwards (Colantonio and Dixon, 2011).

The focus of this paper is on social sustainability and how it is implemented in urban planning. From a semantic perspective, social sustainability can be defined as the ability of a society to sustain itself. It is about people. Naturally, the environmental and economic aspects of sustainability can be achieved thanks to people's ability to sustain their society within their limited resources. In Urban Regeneration and Social Sustainability, Colantonio and Dixon (2011) define social sustainability as how individuals and groups gather together and decide what they want for themselves, taking into account physical boundaries and environmental limits. Manzi et al. (2010) provide a conceptual framework that presents a multidimensional understanding of social sustainability involving the relationship between concepts of participation, justice, democracy ${ }^{2}$ and social cohesion with economic competitiveness and environmental efficiency.

In short, we can suggest that social sustainability reflects the ability of a society to share, maintain and develop its environmental and economic resources in a way that allows social justice, equality and participation within and outside the community, with consideration for the needs of future generations. This paper develops its argument based on the fact that social sustainability depends on human relations. By linking the key concepts embedded in social sustainability with the meaning of public space, I will first discuss how physical public space can contribute to social sustainability, then give examples and discuss the research challenges in this regard.

\section{The meaning of public space}

Patrick Geddes (1854-1932), the Scottish thinker and town planner, talks about giving people places in which they can flourish (Colantonio and Dixon, 2011). These simple words show the nature of the contribution of physical urban spaces to the enhancement of social sustainability. Since the focus of this paper is on public space, I will continue with a short review of various understandings and definitions of public space. Since research on public space has always been interdisciplinary, we will examine the viewpoints of the different disciplines.

2 When Manzi and others use the term democracy they do not refer to a specific understanding of it. In general, they state that terms such as participation and democracy refer to the system of responsibility-sharing in a community. In this paper, democracy is understood as "government by the people exercised either directly or through elected representatives" (American Heritage Dictionary of the English Language, 2000, democracy). 
Many scholars, such as the urban planner Madanipour (2003) and the political scientist Parkinson (2012), call public space the sphere of "interpersonal communication". The urban historian and architect Hayden (1995) explains how social and physical spaces are linked through public spaces that are influential in "social reproduction". ${ }^{4}$ Interpersonal communication which leads to social flourishing and, as Hayden puts it, social reproduction, of course, needs a physical space in which it can take place. This is the most important function and value of public spaces.

Historical public spaces have another important characteristic because of their ability to tell the stories of a society. The idea of "storytelling" is reflected in the literature on historical monuments and urban spaces. For example, according to Hayden (1995), social memory relies on storytelling, and "place memory" can trigger social memory through the urban landscape. ${ }^{5}$ In fact, she believes that memory is "naturally place-oriented" or at least "place-supported", because places engage all human senses (sight, sound, smell, touch and taste), thus making them powerful sources of memory. She argues that the relationship between places and social memory is the key and most powerful reminder to citizens of historical urban places of their public pasts, one that helps them to be connected with those who share a common past. Hayden calls urban landscape a "resource for public history". Similarly, Madanipour (2003) argues that historical public spaces create the opportunity for us to share the experience of being together in the same physical spaces. In his view, being in a historical public space is experienced by past and present generations. If it is conserved, it can be perceived by future generations. In other words, the experience of being in historical public spaces can bond generations.

The above-mentioned factors associated with public space show that physical public spaces are necessary for face-to-face communication among members of a community, as well as for making the latter aware of their common history. This creates solidarity and a sense of belonging to the community, a basis for social sustainability.

Another way to understand the role of physical public spaces in helping societies to flourish is to explore the key concepts used to define public space. As we shall see, scholars in different disciplines define public space in a similar manner, which shows

3 Interpersonal communication is an area of study. In this paper however, it refers simply to the act of exchanging information between two or more human beings through verbal or non-verbal messages. The term "communication" here does not refer to the communication theory, which is also a specific scientific field.

4 Here, Hayden does not give an exact definition for "social reproduction". However, considering the context of her book, one can conclude that by the term "social reproduction" she means the process in which social structures are recreated so that the whole social system can continue.

5 Hayden chooses to use the term "place" instead of space, because for her, place carries the meaning of the special personality of a location in the city, which is why people become attached to that place. 
that the key concepts that construct the meaning of physical public space are commonly agreed upon. A clarification of these definitions also shows how the physical and social components of public space are intertwined and how social sustainability relates to public space at a conceptual level.

Viewing physical public space through a political lens, Parkinson (2012) argues that democracy ${ }^{6}$ depends heavily on the accessibility of "physical public space". Although a political scientist, Parkinson is mainly concerned with physical space, and his definition can help open a discussion on the relation between the social and physical components of public space. Parkinson gives a fourfold definition of physical public space, which takes into consideration its legal, social, political and architectural aspects. In his definition, public space is "openly accessible, and/or uses common resources, and/or has common effects, and/or is used for the performance of public roles" (Parkinson, 2012, p. 16). In this definition, openness, accessibility, and being common are the key attributes of public space.

These attributes are to be found in other definitions. Under the title Common Ground, Orum and Neal (2009) have collected some of the most important literature on public space from disciplines such as sociology, political science, art and urban studies. They define public spaces as "all areas that are open and accessible to all members of the public in a society, in principle though not necessarily in practice" (ibid., p. 2). According to Orum and Neal, a space is open when people are free to use the space regardless of their political opinions, religion, age or gender. A space is accessible when its use is not limited by barriers of language, physical or mental ability or geographic mobility. According to this definition, public spaces are theoretically supposed to be open and accessible to all members of the public, though for reasons such as a lack of facilities or the indirect discouragement of users, they might not meet these criteria. In general, the attributes of openness and accessibility play the key role in their definitions of public space. Of course, as this suggests, openness and accessibility to public space represent a common right for all members of the public.

Madanipour (2003) provides a similar definition of public space, using the criteria of access, agency and interest. In his view, public space is shared by all members of a community, controlled by the public (governmental) authorities, and is open and available to everyone. For Madanipour, the factors that define public space are openness, accessibility or availability, control, and being shared by the community members. However, he argues that a generalized definition of public space becomes "an ideal type", because real-world public spaces may or may not be managed by legitimate agencies, and may or may not be accessible to all members of a community. Therefore, he suggests that a more precise definition of public space would be based on the observation of real-world cases of public spaces. In that sense, the broad discussion

6 Parkinson has a liberal conception of democracy. 
in this paper of the ways in which physical public space contributes to social sustainability would demand a certain amount of nuancing when applied to a specific local context.

In short, public space represents the physical and durable basis for face-to-face interaction of members of society and a basis for social sustainability. In principle, it is where members of a society equally share physical space and the memories associated with it. Public space can tell the shared stories of a society and become a catalyst for solidarity. From the literature reviewed here, it can be concluded that an ideal public space is a space of human communication that allows diversity of people and ideas. Furthermore, historical public spaces can be sources of public history and the collective identity of a society. On an abstract level, the key concepts that construct the meaning of public space are commonness, openness and accessibility. Some authors also point out the notion of equality. Hence it is not surprising that the key concepts of social sustainability (social justice, participation and communication) are hidden in the very meaning of physical public space.

These shared concepts can be seen in urban planning research that attempts to measure or enhance the public-ness of public spaces, or in other words, to study the capacity of public spaces to implement social sustainability. Further on I will give examples showing how the theoretical understanding of social sustainability and the abstract meaning of public space are used in research.

\section{Urban planning approaches that link the social and physical components of public space}

The reviewed scholars of urban planning agree that the forces that shape cities are the market, government, and civil society. Newman and Kenworthy (1999) add urban experts to these forces, as advisors to these three groups. Like many others, they argue that the market and government are of a short-term nature, whereas civil society is the guardian of the values of the community, shaping the society's long-term direction. As a non-governmental and non-profit actor, civil society can represent and safeguard the values of a society without being influenced by political or economic interests. Since a city's public spaces are the main arenas bringing members of the civil society together, we can suggest that the role of urban planning is to facilitate the face-to-face communication of the guardians and long-term directors of the social development process. Of course, this assumption is an optimistic one - in actual fact, the success of a public space strongly depends on the level of equality and the state of democracy of the society using it, a notion reflected in the commonness of control and use of public space, which is a purely political matter. However, urban planning can influence other social aspects of publicness.

Over the twentieth century, schools of thought in architecture and urban planning progressed from functionalism and formalism to more socially sustainable approaches. 
The last century saw the dominance of the modernist approach in urban planning, the creation of rationally structured, automobile-dominated urban spaces divided into areas such as business and residential zones. The outcome of this modernist urbanism was the so-called "auto-city", formed through a top-down planning approach that resulted in environmental and social damage (Newman and Kenworthy, 1999). The shift in urban planning approaches in reaction to the auto-city phenomenon took place in the late twentieth and early twenty-first centuries.

For example, the Sustainable City movement was launched as a reaction to the modernist approach and was concerned with all aspects of sustainability, the environmental in particular. Similarly, urban planning and regeneration movements such as New Urbanism, the Right to the City movement, the launching of "Selfmade City" projects, and the Placemaking movement arose later as a reaction to modern urbanism. These movements commonly advocated the bottom-up approach in urban planning and provided cities with lively and welcoming public spaces for all.

Among these urban planning movements, the Placemaking approach deals more specifically with public space. A short review of its background and methods reveals how urban planning attempts to make a contribution to social sustainable development.

The Placemaking discourse was almost simultaneous with debates on the sustainable city. According to Newman and Kenworthy (1999) and the Massachusetts Institute of Technology (MIT, 2013), academics and professionals who believed in the necessity of changing the modernist approach in urban planning began to advocate improving street life in cities, urban heritage conservation and enhancement of the quality of urban public spaces by creating walkable and pedestrian-friendly rather than car-dominated cities. In short, the aim was to give urban public spaces back to the public.

MIT's 2013 publication on Placemaking gives a useful overview of this approach and its background. According to MIT, the movement began in the 1960s in the United States through the efforts of a group of urban thinkers, among whom were Jane Jacobs, Kevin Lynch, Christopher Alexander and William Whyte. The core of the Placemaking approach is the creation of places by people and for people, the urban planner considered only as an adviser body. It advocates the fundamental right of citizens to the city and concerns issues such as healthy living thanks to safe and fun public spaces. It also encourages the use of existing resources through urban heritage conservation (ibid., 2013).

7 The idea of "Selfmade City" is also one of the urban planning approaches that considers social and economic issues of urban governance and focuses on small-scale projects. This approach advocates the right of local people to shape the urban space they live in. For example, Selfmade City, Self-Initiated Urban Living and Architectural Interventions, edited by Kristien Ring (2013), introduces the "Selfmade City" approach and shows sample projects in Berlin. 
The methods used in the Placemaking approach are mainly based on behavioural observations. In The Social Life of Small Urban Spaces, Whyte (1980) provides a detailed analysis of public life in plazas by observing what people do and interviewing them. His main data-collecting method is behavioural observation through time-lapse cameras.

Inspired by Whyte's work based on observations and interviews, a group of professionals and researchers following the Placemaking approach have developed a set of indicators for assessing the capability of public spaces to host public life. The tools they use for this purpose are introduced in their official web page, Project for Public Spaces. ${ }^{8}$ They categorize their indicators under the four attributes of sociability, uses and activity, access and linkage, and comfort and image. In this framework, the number of women, children and elderly, identifiable social networks, volunteerism, evening use and street life in urban spaces indicate their sociability. To assess uses and activity they study factors such as land-use patterns, property values and rent levels. For access and linkage, they use indicators such as traffic data, pedestrian activities and parking usage patterns. Finally, for assessing comfort and image, they study crime statistics, the sanitation rating of spaces, built and natural environmental data.

In the following section I will provide examples illustrating how social life is studied in public spaces, and how the ability of public spaces to host sustainable social life is evaluated.

\section{Methods used in empirical research on social sustainability in public space}

Today, sustainability indicator checklists are tools used by governments to assess urban planning projects in many countries. Before discussing a few research-based examples of the use of these indicators, I would like to say a few words about a work on the broader understanding of social sustainability in the urban context. In Social Sustainability in Urban Areas, Manzi et al. (2010) present a collection of published articles. The case studies they present are mainly of a qualitative nature and interest me for two reasons. First, they present the Egan Wheel as a tool for evaluating the social sustainability of communities. The Egan Wheel shows the capacities of a community to develop social sustainability, thus helping to understand which aspects of social sustainability can (theoretically) be enhanced by a well-designed and high-quality built environment, as well as an active and inclusive social and cultural life. The Egan Wheel provides a schematic view of how social sustainability is seen through the lens of urban planning (Figure 1). Second, although in the Egan Wheel the influ-

8 http://www.pps.org/ 


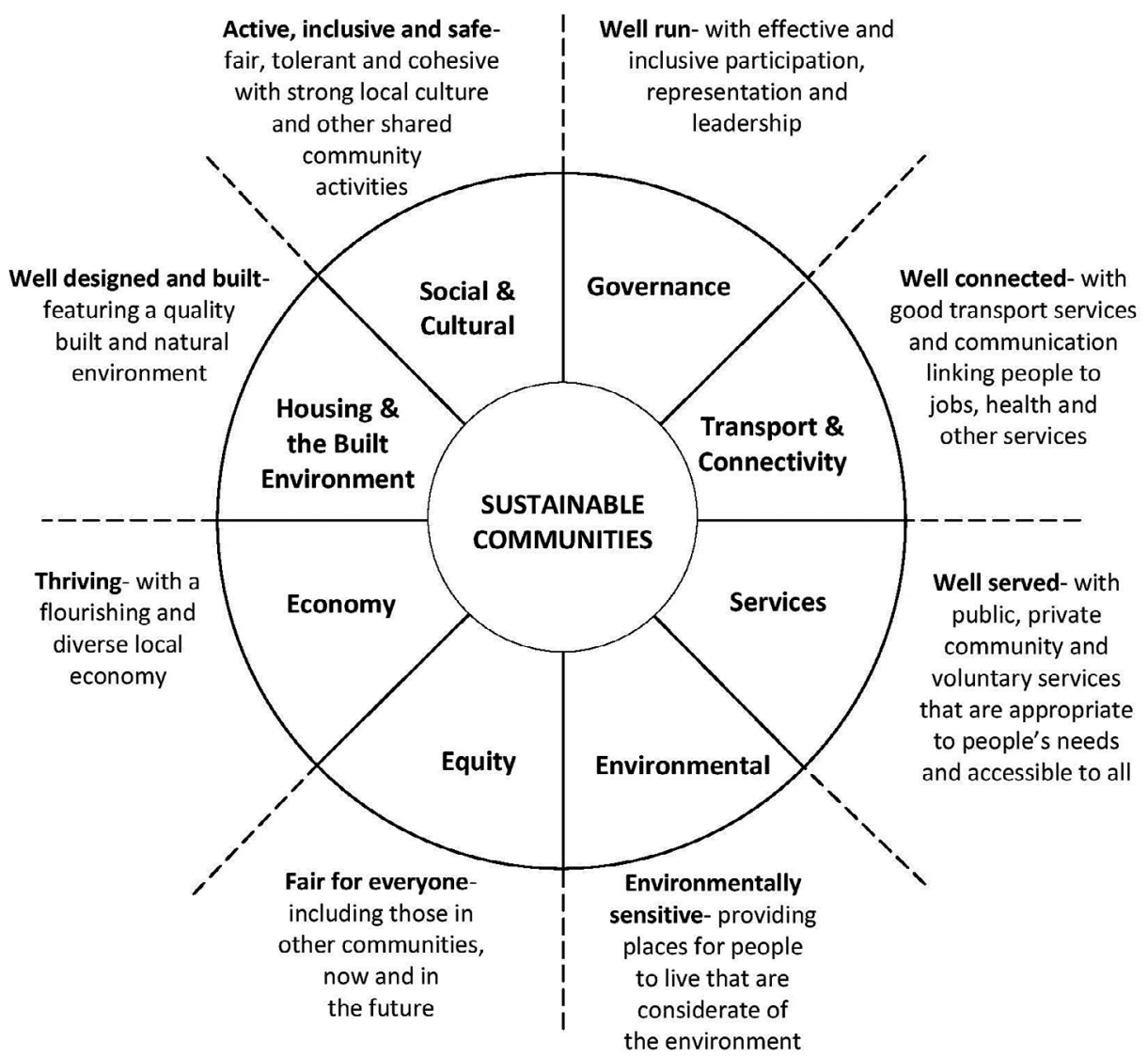

Fig. 1: The Egan Wheel presentation of skills for implementing social sustainability (Manzi et al., 2010, p.17)

ence of "the quality and design of the built environment" on social sustainability is mentioned, no concrete outcome is presented that could indicate how this influence can actually be studied. The collection of articles evidences the gap as concerns the relationship between the design and the physical aspects of urban spaces, and social sustainability.

Among the examples of research attempting to study how the physical characteristics of urban spaces influence social life we can cite that of Gehl (1989; 2013), who conducted street-life observation in Copenhagen in view of the extension of pedestrian zones. Gehl studied how social change has led to changes in the patterns of use of public spaces in the historic centre of Copenhagen. He sees public spaces as places for "direct communication" and "cultural exchange". As he sees it, the city resembles a "party" for which he advocates the free enjoyment of all (Gehl, 1989). 
The Copenhagen studies included several projects. One was the research project for studying public life in Strøget, a pedestrian street located in the historic centre of Copenhagen, which began in 1967. In How to Study Public Life, Gehl and Svarre (2013) explain how the Strøget project was used as an urban laboratory to observe the patterns of use of public space. Observations would document how the street functioned normally and during certain particular days and events. Gehl's methods are mainly based on the behavioural observation of pedestrians. In this methodological framework, the researcher would trace individual public space users or observe large groups of users, writing field notes and taking pictures to document the routes used, the times, pleasures and problems (ibid., 2013) that occurred.

For example, the relationship between pedestrian flow (number of people/minute) and the activity level of the street (number of people on 100 metres of street) was studied to evaluate the changes in street life throughout the year. Naturally, a low rate of flow shows that people are standing, moving slowly and talking, which indicates a greater possibility of social interaction. Gehl discovered that during summer or when a cultural event is taking place and in the absence of automobiles, public places offer a greater possibility for social interaction (ibid., 2013). In his series of studies in Copenhagen, Gehl also ascertained that there is a direct relation between "the physical qualities of public space and the volume and character of life there” (Gehl, 1989, p.15). Doubtless, Gehl's works are among the most important contributions to research on public space and its relation with social life, and although his publications are not directly focused on the relationship of social sustainability and urban design, his methods for studying public spaces are widely used in the field.

Porta and Renne's (2005) research attempts to introduce indicators for measuring social sustainability in urban settings. Their work is the result of literature review and field research in Western Australia. They introduce the concept of formal indicators to quantitatively evaluate the design of streets in terms of their ability to promote certain activities and encourage people to walk or drive. Through these indicators, they attempt to quantify the design component of spaces on urban fabric and street scales.

On an urban fabric scale, they suggest indicators of accessibility, land-use diversity, legibility of public and private realms, natural surveillance (security), permeability (street connectivity), employment density, number of buildings and number of lots to assess social sustainability. At this level, for example, through front and back mapping, they identify areas of the street that have active frontage, indicating safety. Regarding the level of permeability, they suggest that urban layout should contain a high proportion of four-way intersections.

On street scale, Porta and Renne's (2005) measurement system suggests a set of indicators showing the architectural qualities of the urban spaces in the streets of Joondalup and Fremantle (Western Australia). One of the suggested street indicators is sky exposure, in an attempt to understand the urban environment's ability to encapsulate the pedestrian, and to evaluate the level of street intimacy. Other indicators 
are facade continuity, softness (transparency of spaces which makes a street safe and welcoming), social width (allowing human interaction), visual complexity, number of buildings, sedibility and detractors (such as large blank walls, aggressive automobile facilities, parking lots and billboards).

Their research suggests that the traditional urban fabric of Fremantle was more user-friendly than the newly developed Joondalup area. They conclude with ten rules that advise designing narrow streets, not isolating buildings, designing continuous frontages, increasing the number of small buildings instead of building a few large ones, putting retail businesses on the ground floor, avoiding parking lots, creating a soft transition from the street to the building, avoiding blank walls and large billboards, putting trees on wide streets, and providing sedible spaces.

The conclusions of this measurement system are largely based on quantified visual values and take other human senses much less into consideration. Although their criteria provide a description of the streetscape, qualities such as street intimacy or safe and welcoming streets are extremely subjective at cultural and individual levels. Therefore, this method can be used as a basis for further qualitative studies based on user opinions and perceptions. As for its applicability to other places, considering the time and funding needed for such surveys, it would seem most applicable at the urban fabric level, mainly carried out on the basis of maps. Given that assessments in street scale are largely based on the work of an operator quantifying data hidden in several pictures of streets, the results can be influenced by the subjective judgments of the operator. Nonetheless, this a good example of the strengths and weaknesses of currently used methods of studying the relation between urban form and social sustainability.

In the field of urban heritage conservation, the state of literature is no different from that of urban planning. The review conducted by Ryberg-Webster and Kinahan (2014) shows the gaps in urban heritage conservation research. Viewing urban preservation as a key driver of urban revitalization, Ryberg-Webster and Kinahan believe that heritage is linked to sustainability and can be used in the transformation of cities. They refer to several urban conservation research works, suggesting that built heritage can develop a sense of place, enhance quality of life and offer a unique community attachment. However, they acknowledge that there is a dearth of empirical research to support these claims. Arguing that preservation should be present at economic and community development debates, they state that preservationists should "come to the table with new ideas and data to support their arguments" (RybergWebster and Kinahan, 2014, p. 29).

The works reviewed in the above are based on indicator-based methods supported by behavioural observations, interviews, and observation of the built environment. Each example focuses mainly on one or two of these techniques. Using a mixture of interview and participant observation techniques and observation of the physical characteristics of the built environment can link physical and social components of public space. The same argument can be made regarding qualitative and quantitative 
methods. For example, in urban fabric and district level studies, quantitative data can provide more useful evidence, while at the street level, a qualitative understanding from the perspective of users is more helpful. Briefly, when the research question is related to social life, the triangulation of data collected through different methods can be used to establish a useful research framework.

\section{The outlook for public space research}

Social sustainability involves setting the needs and limits of a society in an ethical framework. As mentioned earlier, it takes into consideration principles such as social justice, social cohesion, participation, and the rights of future generations to enjoy the environmental and cultural resources. Conceptually speaking, public space values and nurtures those same principles by advocating equal accessibility and the openness to all of shared urban spaces, and by providing physical space for communication among diverse groups of people. The authors reviewed also point out the unique power of historical public spaces as urban heritage - sources of public history and collective identity.

Thanks to the works of urban theorists, there is no need today, to justify the importance of the physical components of public space in social sustainability - at least at a theoretical level. However, when it comes to empirical research, there remains a challenge: indeed, the weakness of current public space research is more apparent in methodological matters than in theoretical matters.

The reviewed examples of research in urban planning have in fact been developed to assess and implement the shared principle of social sustainability and public space. Through the assessment of equal openness and accessibility, land-use diversity, activity level, user-friendliness and safety of urban spaces, an attempt is made to concretize values such as diversity, equality, health, and safety in urban social life. Nevertheless, the field lacks a more comprehensive methodological framework, if it is to embrace and integrate the social and physical aspects of historical public spaces.

The empirical examples usually categorize the characteristics of public spaces in terms of measurable indicators, on the basis of which the ability of the physical space to host public life is assessed. By means of interviews and observation of the built environment, these methods obviously help formulate a functional assessment of public spaces so far as meeting user needs is concerned. However, the implementation of social sustainability/public space principles requires more practical methods that would explain and assess the qualitative characters of public spaces and how they actually contribute to social sustainability. In order to scientifically prove the ability of historical public spaces to foster characteristics such as place attachment and collective identity, further research is definitely needed in the field of urban heritage conservation. Public space research is by nature interdisciplinary, and its epistemological and methodological approach has been enriched by other disciplines; never- 
theless, further methodological developments are necessary to enhance our knowledge of the relationship between human beings and physical spaces, and how the sense of belonging to a shared place can strengthen the sense of belonging to a community.

It is certain that the knowledge provided by various case studies is extremely helpful in understanding the correlations involving social sustainability and historical public spaces. However, different cultural contexts may have different understandings of the concept of social sustainability and the meaning of public space. As a result, along with the findings of previous case-study research, we need methods based on local observations, with attention paid to how social sustainability is related to local economic and environmental sustainability.

\section{References}

Albert, M.-T. 2013. Heritage studies. Paradigmatic reflections. In: Albert et al., op cit., pp.9-17. Albert, M.-T., Bernecker, R. and Rudolff, B. (eds). 2013. Understanding Heritage: Perspectives in Heritage Studies. Berlin, De Gruyter. (Heritage Studies Vol.1.)

Bandarin, F. 2012. From paradox to paradigm: Historic Urban Landscape as an urban conservation approach. In: Managing Cultural Landscapes. London/New York, Routledge, Taylor and Francis Group, pp. 213-31.

Colantonio, A. and Dixon, T. 2011. Urban Regeneration and Social Sustainability: Best Practice from European Cities. Oxford, UK, Wiley-Blackwell.

Gehl, J. 1989. A changing street life in a changing society. Places Journal, Vol. 6, No.1, pp. 8-17.

Gehl, J. and Svarre, B. 2013. How to Study Public Life. Washington DC/Covelo, Calif./London, Island Press.

Hayden, D. 1995. The Power of Place: Urban Landscapes as Public History. Cambridge, Mass., MIT Press.

Madanipour. 2003. Public and Private Spaces of the City. London, Routledge.

Manzi, T., Lucas, K., Jones, T. L. and Allen, J. 2010. Social Sustainability in Urban Areas. London/ Washington DC, Earthscan.

MIT. 2013. Places in the Making: How Placemaking Builds Places and Communities. Cambridge, Mass., Department of Urban Studies and Planning, Massachusetts Institute of Technology.

Newman, P. and Kenworthy, J. 1999. Sustainability and Cities, overcoming automobile dependence. Washington DC/Covelo, Calif., Island Press.

Orum, A. M. and Neal, Z. P. 2009. Common Ground? Readings and Reflections on Public Space, New York/London, Routledge.

Parkinson, J. 2012. Democracy and Public Space, The Physical Sites of Democratic Performance. New York, Oxford University Press.

Porta, S. and Renne, J. L. 2005. Linking urban design to sustainability: formal indicators of social urban sustainability field research in Perth, Western Australia. Urban Design International, Vol.10, No.1. pp.51-64.

Ring, K. (ed.). 2013. Selfmade City, Self-Initiated Urban Living and Architectural Interventions. Berlin, Jovis Publishers.

Ryberg-Webster, S. and Kinahan, K. L. 2014. Historic preservation and urban revitalization in the twenty-first century, Journal of Planning Literature, Vol. 29, No. 2, pp.119-39.

The American Heritage Dictionary of the English language. 2000. http://www.thefreedictionary. com/democracy (Accessed 4 December 2014.) 
Turner, M. 2013. UNESCO Recommendation on the Historic Urban Landscape. In: Albert et al., op cit., pp. 77-87.

UNESCO. 2011. Recommendation on the Historic Urban Landscape, including a glossary of definitions. http://portal.unesco.org/en/ev.php-URL_ID=48857\&URL_DO=DO_TOPIC\&URL_ SECTION=201.html (Accessed 11 December 2014.)

UNDP. 2014. Human Development Report. Sustaining Human Progress: Reducing Vulnerabilities and Building Resilience. New York, United Nations Development Programme. http/hdr.undp.org/en/2014-report (Accessed 13 December 2014.)

WCED. 1987. Report of the World Commission on Environment and Development. Our Common Future. (Brundtland Report). New York, United Nations. http://www.un-documents.net/ wced-ocf.htm

Whyte, W. H.1980. The Social Life of Small Urban Spaces. Washington DC, Conservation Foundation. 